\title{
Meta-analysis of the safety of voriconazole in definitive, empirical, and prophylactic therapies for invasive fungal infections
}

\author{
Yuanming Xing ${ }^{1,2 \dagger}$, Lu Chen $^{3 \dagger}$, Yan Feng ${ }^{1,2}$, Yan Zhou ${ }^{1,4}$, Yajing Zhai ${ }^{1}$ and Jun Lu ${ }^{1 *}$
}

\begin{abstract}
Background: Voriconazole has been used in the treatment and prophylaxis of invasive fungal infections (IFIs) while its wide use was limited by some frequent adverse events, especially neurotoxicity, hepatotoxicity and even renal disruption. The aim of this study was to comprehensively compare voriconazole-induced toxicity, including tolerability, neurotoxicity, visual toxicity, hepatotoxicity and nephrotoxicity with the composite of other antifungals commonly used in clinic.

Methods: Bibliography databases were searched to select randomized controlled trials providing information about the incidence of toxicity referred above. A total of 4122 patients from 16 studies were included in the meta-analysis.

Results: Analysis of individual types of toxicity showed that there was a significant difference between voriconazole and the composite of other antifungal agents. The primary outcome, the tolerability of voriconazole was slightly inferior $(\mathrm{OR}=1.71,95 \% \mathrm{Cl}=1.21-2.40, P=0.002)$ and it is noteworthy that the probabilities of neurotoxicity and visual toxicity were around twice higher and six-fold for voriconazole compared with the counterpart ( $\mathrm{OR}=1.99$, $95 \% \mathrm{Cl}=1.05-3.75, P=0.03$ and $\mathrm{OR}=6.50,95 \% \mathrm{Cl}=2.93-14.41, P<0.00001$, respectively). Hepatotoxicity was more common in voriconazole group $(\mathrm{OR}=1.60,95 \% \mathrm{Cl}=1.17-2.19, P=0.003)$ whereas its pooled risk of nephrotoxicity was about half of the composite of other five antifungal agents $(\mathrm{OR}=0.46,95 \% \mathrm{Cl}=0.26-0.84, P=0.01)$.

Conclusion: Our analysis has revealed differences in multiple types of toxicity induced by VRC versus other antifungals and quantified the corresponding pooled risks, which could provide an alternative for patients with a certain antifungal intolerance and help the clinician to select the optimal intervention.
\end{abstract}

Keywords: Voriconazole, Invasive fungal infections, Tolerability, Meta-analysis

\section{Background}

Invasive fungal infections (IFIs) remain a leading cause of morbidity and mortality in immunodeficient critically ill patients. Prophylaxis usually recommended for those patients with unidentified diagnosis but with high risk factors. Empirical antifungal therapy is usually suggested to treat probable and possible IFIs. A definitive therapy is permitted only for the definitive diagnosis as proven fungal infection. The abovementioned three levels of IFI diagnosis were defined according to the EORTC/MSG criteria [1].

\footnotetext{
* Correspondence: 2576042020@qq.com

${ }^{\dagger}$ Equal contributors

${ }^{1}$ Clinical Research Center, The First Affiliated Hospital of Xi'an Jiaotong

University, Xi'an 710061, China

Full list of author information is available at the end of the article
}

Amphotericin $\mathrm{B}(\mathrm{AMB})$, triazoles including itraconazole, voriconazole (VRC), posaconazole, isavuconazole as well as combination antifungal therapy with voriconazole and an echinocandin are preferred agents for treatment and prevention of invasive aspergillosis in most patients [2]. Fluconazole and echinocandin including caspofungin, micafungin and anidulafungin are usually recommended for invasive candidiasis while some triazole and AMB are also recommended if there is intolerance limited availability, or resistance to other antifungal agents [3].

Voriconazole is a second-generation triazole antifungal agent that is effective against an IDSA diverse array of fungi, including Candida, Aspergillus, Scedosporium, and Fusarium spp. It is recommended as the first-line 
treatment for invasive aspergillosis by the Infectious Diseases Society of America [2, 4] and is also used in definitive and prophylatic therapies for Candida spp. and other molds $[3,5]$. However, the universal use of this agent has been restricted by the high frequency of adverse events such as neurotoxicity, visual toxicity, and hepatotoxicity and the potential for nephrotoxicity caused by a cyclodextrin-based vehicle in its intravenous formulation; any of these types of toxicity may lead to discontinuation during treatment [6-8].

While individual reviews of different antifungals have been reported [8-15], there has been no systematic comprehensive comparison of the safety of VRC and other antifungal agents. A systematic review from 2010 individually compared the risk of discontinuation and hepatotoxicity of six antifungals in definitive and empirical therapies for IFIs [4]. Due to its indirect parallels between VRC and other antifungal agents as well as the limited toxicity, its findings need to be clarified and updated. We therefore performed a comprehensive meta-analysis of all relevant data in randomized controlled trials (RCTs) in order to gain a better understanding of the main toxicity profiles for VRC and other antifungals used in definitive, empirical, and prophylactic therapies for IFIs.

\section{Methods}

\section{Search strategy}

We conducted a literature search of PubMed, Embase, and the Cochrane Library from their inceptions up to December 15, 2016. An additional manual literature search was performed by checking the reference lists in eligible articles. The MeSH terms used for keyword and text-word searches were "antifungal agents" and "voriconazole". The search was limited to human studies.

\section{Selection criteria}

Two reviewers independently evaluated each study and identified whether they met the predefined inclusion criteria. We used the PRISMA criteria for searching and selecting studies (Fig. 1). The following inclusion criteria were applied to identify eligible studies: (i) published in the English language before December 15, 2016; (ii) designed as an RCT; (iii) comparing the safety between VRC and other antifungal agents in definitive, empirical, or prophylactic therapy for IFIs; and (iv) providing the incidence of toxicity at least one term among discontinuation, neurotoxicity, visual toxicity, hepatotoxicity, or nephrotoxicity. We excluded studies that enrolled only pediatric patients, studies only focusing on superficial or mucocutaneous fungal infection, and studies of pharmacokinetics, clinical efficacy, and mycology.

\section{Safety outcomes}

The primary outcome was the proportion of patients who discontinued antifungal therapy due to adverse events. The secondary outcome of interest was the cumulative incidence of adverse events related to neurotoxicity, including headache, dizziness, restlessness, hallucination, insomnia and depression and some other nervous system disorders and psychiatric disorders according to version 4.0 of the Common Terminology Criteria for Adverse Events (CTCAE) [16]. Another secondary outcome is visual toxicity which was defined as the occurrence of abnormal vision, photophobia, chromatopsia and some other eye disorders according to CTCAE. We also evaluated the cumulative incidence of laboratory tests of liver dysfunction (serum transaminase, alanine transaminase, alkaline phosphatase, or bilirubin levels) and renal dysfunction (serum creatinine), which represented the safety outcomes of hepatotoxicity and nephrotoxicity. We directly used the laboratory test cutoff values reported for individual studies, since the criteria varied among the different studies.

\section{Data extraction and quality assessment}

Two reviewers independently extracted specific information from studies, including year of publication, authors, study design, therapeutic purposes, antifungals administered, sample size, age, underlying diseases, dose and duration of administration, and safety outcomes including tolerability, neurotoxicity, visual toxicity, hepatotoxicity, and nephrotoxicity. Disagreements about the specific data between two reviewers were resolved through consensus. We attempted to contact the authors by email to seek required data that were missing from the original reports.

Two investigators independently appraised the sources of bias in RCTs according to the Cochrane Collaboration guidelines, and classified each RCT into low, unclear, or high risk by evaluating the following domains: random sequence generation, allocation concealment, blinding of participants and outcome assessment, incomplete outcome data, selective outcome reporting, and other issues [17]. Discrepancies were resolved by discussion with a third investigator. RCTs for which two or more domains were judged as having a high or unclear risk were regarded as having a high overall risk of bias.

\section{Statistical analysis}

We compared the following five safety outcomes between VRC and other antifungal agents: (1) the proportion of antifungal discontinuations due to adverse events, and the cumulative incidences of neurotoxic events related to (2) nervous system and psychiatric disorders and (3) eye disorders (4) liver and (5) renal dysfunction. We performed subgroup analysis to 


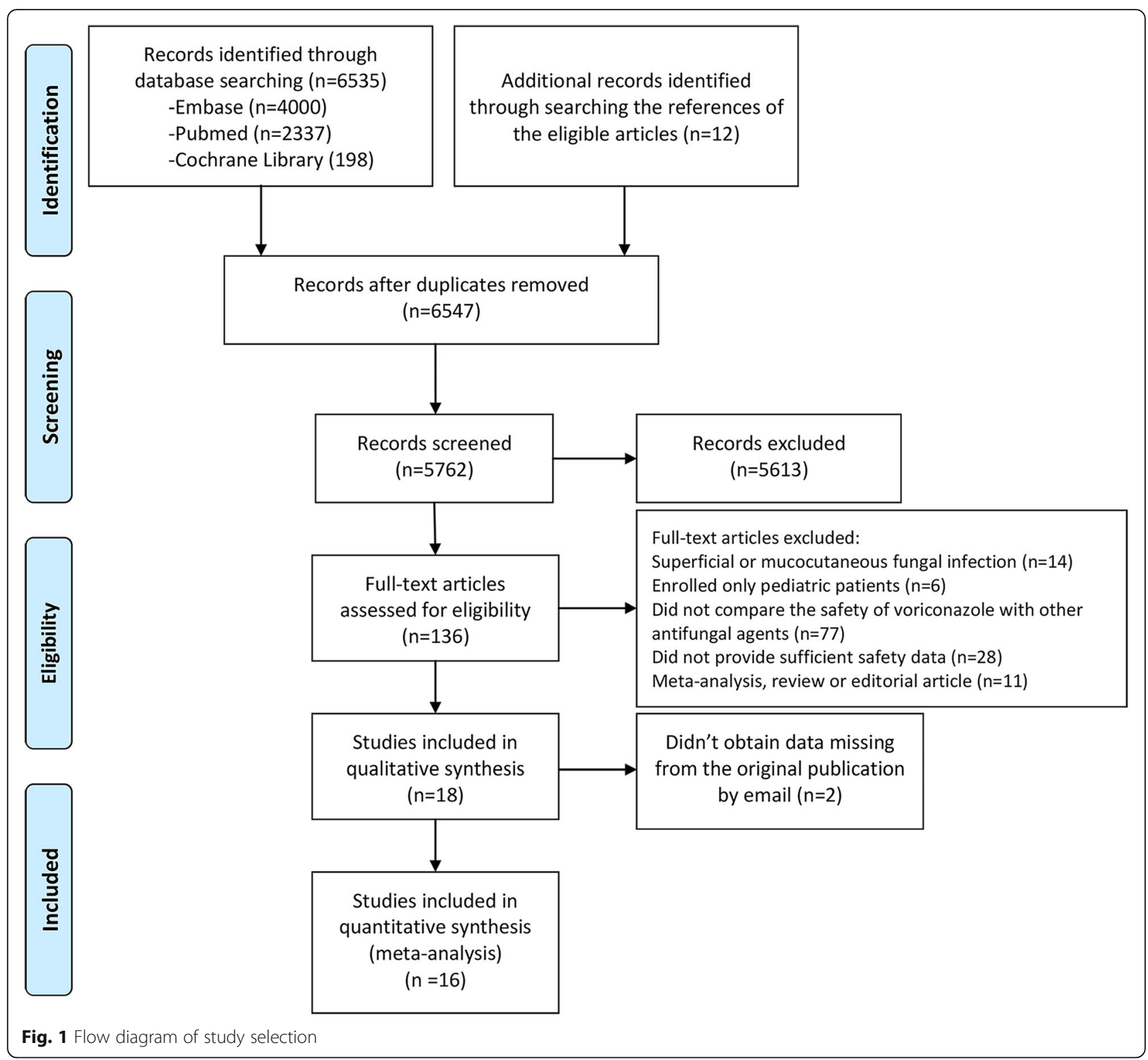

determine if the final results were influenced by certain factors, including different antifungals, therapeutic purpose (definitive, empirical, or prophylactic therapy), and duration ( $<14$ days and $\geq 14$ days). Odds ratios (ORs) and 95\% confidence intervals (CIs) were estimated for subgroups with more than two studies. We also performed a sensitivity analysis to examine the stability of the results by excluding a single or multiple studies that were classified by a specific criterion, such as a small sample $(n<50)$, single-center design, or high risk of bias.

A two-sided $P$ value of $<0.05$ was considered indicative of statistical significance. All statistical analyses were performed using RevMan (version 5.3) and Stata (version 12.0, StataCorp, College Station, TX).

\section{Results}

Study selection and characteristics of included researches The electronic and manual searches identified 6547 studies, of which 16 RCTs [18-33] involving 4122 randomized patients met the criteria and so were entered into the final analysis (Table 1). A flow diagram of the study selection process is shown in Fig. 1 (see more detailed searching strategy in Additional file 1). The safety outcomes for tolerability, neurotoxicity, visual toxicity, hepatotoxicity, and nephrotoxicity were reported for 12, 10, 13, 14, and 9 studies, respectively. The main underlying disease of patients in the included RCTs was hematological malignancy, followed by solid cancers and other diseases with a high risk of fungal infection. The antifungal agents used in the counterpart groups 
Table 1 Characteristics of included studies

\begin{tabular}{|c|c|c|c|c|c|c|c|c|c|}
\hline Year & Author & Multicenter & Therapeutic purpose & Antifungals & Sample size & Age & Underlying Disease & Dosing regimen & Duration \\
\hline \multirow[t]{2}{*}{2001} & Ally & Y & $\mathrm{D}$ & VRC & 200 & $18-75$ & $\begin{array}{l}\text { Esophageal Candidiasis, } \\
\text { AIDS }\end{array}$ & 200 mg, oral, bid & $14 d$ \\
\hline & & & & FLU & 191 & $18-76$ & $\begin{array}{l}\text { Esophageal Candidiasis, } \\
\text { AIDS }\end{array}$ & $200 \mathrm{mg}$, oral, qd & $15 d$ \\
\hline \multirow[t]{2}{*}{2002} & Lazarus & Y & $P$ & VRC & 18 & $23-61$ & HM \& solid tumor & 200/300 mg, oral, q12h & $14 d$ \\
\hline & & & & FLU & 6 & $23-62$ & HM \& solid tumor & 400 mg, oral, qd & $14 d$ \\
\hline \multirow[t]{2}{*}{2002} & Herbrecht & Y & D & VRC & 144 & 48.5 & HM, SOT, AIDS & 200 mg, oral/i.v., bid & $77 d$ \\
\hline & & & & AMBD & 133 & 50.5 & HM, SOT, AIDS & $1-1.5 \mathrm{mg} / \mathrm{kg}$, i.v., qd & $10 d$ \\
\hline \multirow[t]{2}{*}{2002} & Walsh & Y & $\mathrm{E}$ & VRC & 415 & 46.3 & $\mathrm{FN}, \mathrm{HM}$ or other cancers & 200 mg, oral, q12h & $7 d$ \\
\hline & & & & LAMB & 422 & 45 & $\mathrm{FN}, \mathrm{HM}$ or other cancers & $3 \mathrm{mg} / \mathrm{kg}$, i.v. qd & $7 d$ \\
\hline \multirow[t]{3}{*}{2005} & Kullberg & Y & D & VRC & 248 & 53.6 & Candidaemia & $200 \mathrm{mg}$, bid & $15 d$ \\
\hline & & & & $\mathrm{AMB} / \mathrm{FLU}$ & 122 & 53.3 & Candidaemia & $\begin{array}{l}\text { AMB } 0.7-1.0 \mathrm{mg} / \mathrm{kg} \text {, } \\
\text { oral/i.v., qd, }\end{array}$ & $15 d$ \\
\hline & & & & & & & & Flu, 400 mg, oral/i.v. qd & \\
\hline \multirow[t]{2}{*}{2007} & Queiroz-Telles & Y & D & VRC & 35 & 48.3 & Paracoccidioidomycosis & 200 mg, oral, bid & $169 d$ \\
\hline & & & & ITRA & 18 & 48.7 & Paracoccidioidomycosis & 100 mg, oral, bid & $200 d$ \\
\hline \multirow[t]{2}{*}{2010} & Wingard & Y & $P$ & VRC & 305 & 43 & AHSCT & 200 mg, oral, bid & $100 d$ \\
\hline & & & & FLU & 295 & 43 & AHSCT & 400 mg, oral, qd & $100 d$ \\
\hline \multirow[t]{2}{*}{2010} & Kohno. & Y & D & VRC & 54 & 69.9 & Tuberculosis sequelae & $4 \mathrm{mg} / \mathrm{kg}$, i.v., bid & $3 w$ \\
\hline & & & & MCF & 53 & 72.1 & Tuberculosis sequelae & 150-300 mg, i.v., qd & $3 w$ \\
\hline \multirow[t]{2}{*}{2010} & Oyake 1 & Y & $\mathrm{E}$ & VRC & 46 & NA & FN patients with AML & $4 \mathrm{mg} / \mathrm{kg}$, i.v., bid & $9 d$ \\
\hline & & & & MCF & 49 & NA & FN patients with AML & 150 mg, i.v., qd & $10 d$ \\
\hline \multirow[t]{2}{*}{2011} & Bansal & N & $\mathrm{D}$ & VRC & 15 & 36.3 & CISA & $\begin{array}{l}200 \mathrm{mg} \text { (adults), } 100 \mathrm{mg} \\
\text { (children), oral, q12h; }\end{array}$ & $12 w$ \\
\hline & & & & AMB & 18 & 36.3 & CISA & $1 \mathrm{mg} / \mathrm{kg}$, i.v., qd & $14 w$ \\
\hline \multirow[t]{2}{*}{2011} & Mattiuzzi & N & $P$ & VRC & 71 & 36.3 & $\mathrm{AML}+\mathrm{MDS}$ & 300 mg, i.v., bid & $20 d$ \\
\hline & & & & ITRA & 52 & 60 & $\mathrm{AML}+\mathrm{MDS}$ & 200 mg, i.v., qd & $21 d$ \\
\hline \multirow[t]{3}{*}{2012} & Shang & Y & D & VRC & 34 & 37.5 & Kidney transplant & $4 \mathrm{mg} / \mathrm{kg}$, i.v., q12h & $2.9 \mathrm{~m}$ \\
\hline & & & & MCF & 31 & 39.2 & Kidney transplant & 100 mg (<60 kg), qd; & $3.8 \mathrm{~m}$ \\
\hline & & & & & & & & $150 \mathrm{mg}$ (>60 kg), i.v., gd & \\
\hline \multirow[t]{2}{*}{2013} & Gao & Y & $P$ & VRC & 224 & 42.3 & AHSCT & 200/100 mg, oral/i.v., bid & $96 d$ \\
\hline & & & & ITRA & 241 & 42.3 & AHSCT & 200 mg, oral/i.v., bid & $68 d$ \\
\hline \multirow[t]{2}{*}{2014} & Hayashi & Y & $P$ & VRC & 33 & NA & AHSCT & 200 mg, oral, bid & NA \\
\hline & & & & ITRA & 33 & NA & AHSCT & $2.5 \mathrm{mg} / \mathrm{kg}$, oral/i.v., bid & NA \\
\hline \multirow[t]{2}{*}{2016} & Maertens & Y & $\mathrm{D}$ & VRC & 258 & 51.2 & HM & $\begin{array}{l}4 \mathrm{mg} / \mathrm{kg} / 200 \mathrm{mg} \text {, } \\
\text { oral/i.v., bid }\end{array}$ & $47 d$ \\
\hline & & & & ISA & 258 & 51.1 & $\mathrm{HM}$ & 200 mg, oral/i.v., qd & $45 d$ \\
\hline \multirow[t]{2}{*}{2016} & Oyake 2 & Y & $\mathrm{E}$ & VRC & 50 & 53 & FN with hematopathy & 4 mg/kg, i.v., bid & $9 d$ \\
\hline & & & & MCF & 50 & 53 & FN with hematopathy & 150 mg, i.v., qd & $12 d$ \\
\hline
\end{tabular}

$Y$ Yes, $N$ No, NA not available, $D$ definitive treatment, $E$ empirical treatment, $P$ prophylaxis, $V R C$ voriconazole, $F L U$ fluconazole, $A M B D$ amphotericin $B$ deoxycholate, LAMB liposome amphotericin B, AMB amphotericin B, ITRA itraconazole, MCF micafungin, ISA isavuconazole, HM hematological malignancy, SOT solid organ transplantation, FN febrile neutropenia, AHSCT allogeneic hematopoietic stem cell transplantation, $A M L$ acute myeloid leukemia, CISA chronic invasive sinus aspergillosis, MDS myelodysplastic syndrome

included fluconazole $(n=3)$, amphotericin B $(n=3)$, itraconazole $(n=4)$, micafungin $(n=4)$, isavuconazole $(n=1)$, and a combination of fluconazole and AMB $(n=1)$. There were eight, three, and five studies that had definitive, empirical, and prophylactic treatment purposes, respectively. The duration of drug therapy was at least
2 weeks in 12 RCTs, less than 2 weeks in 3 RCTs, and unknown in the remaining RCTs.

\section{Bias assessment}

Figure 2 presents the results of the systematic bias analysis. There was a low risk of bias for most items, except 


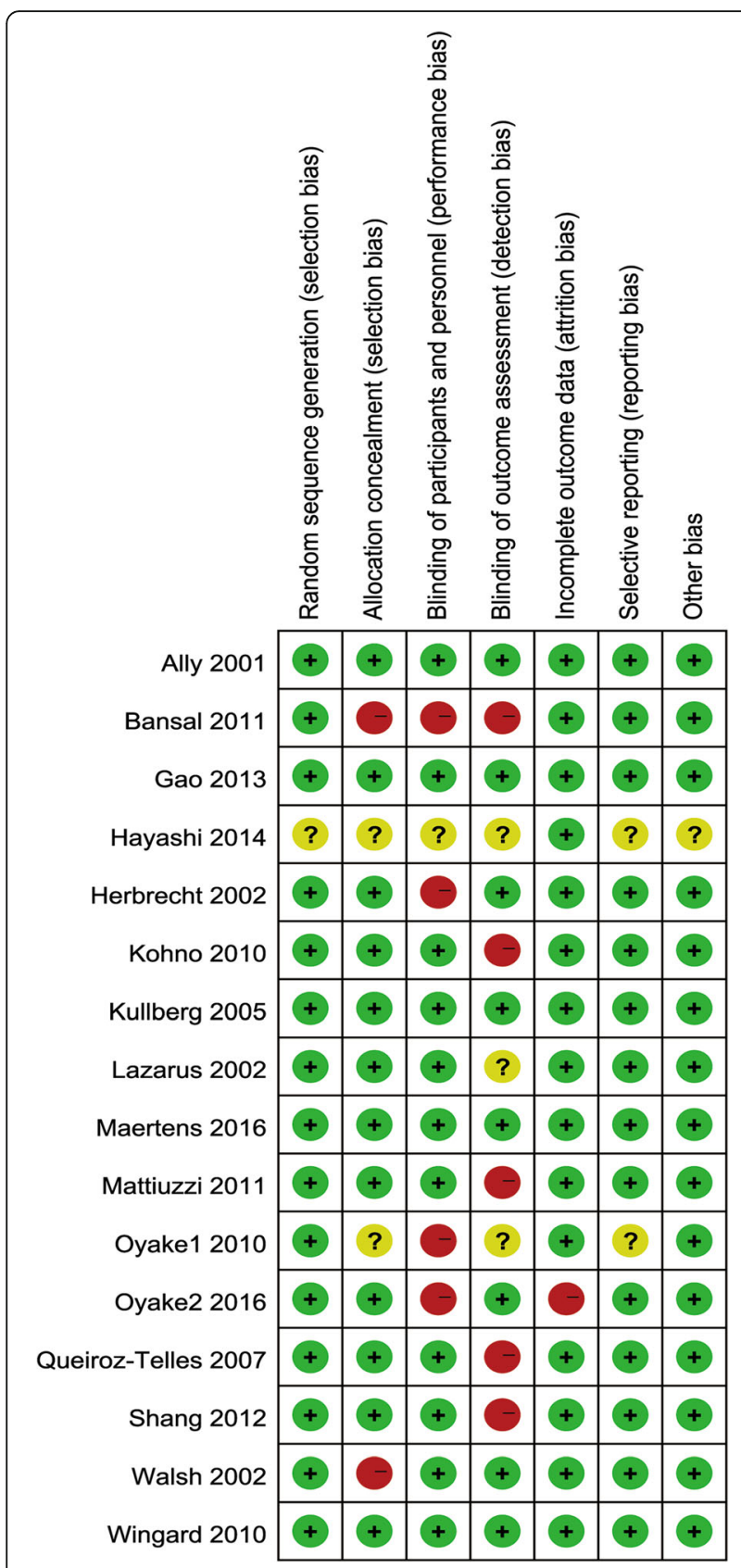

Fig. 2 Risk of bias summary: review authors' judgments about each risk of bias item for each included study

for the presence of performance and detection bias due to the lack of a double-blind design and blind outcome assessment in four studies [18, 22, 27, 32].

\section{Safety outcomes Tolerability}

Tolerability could be analyzed for 12 RCTs involving 2146 patients [20, 21, 23, 24, 26-33]. VRC was associated with a higher probability of discontinuation due to adverse events compared with the composite of other antifungal agents ( $13.2 \%$ vs. $9.8 \%)(\mathrm{OR}=1.71,95 \% \mathrm{CI}=1.21-$ 2.40, $P=0.002 ; I^{2}=32 \%$ ) (Fig. 3).

\section{Neurotoxicity}

Neurotoxicity could be analyzed for 10 RCTs involving 3036 patients [19, 21, 24, 26, 28-33]. Compared with other antifungal agents, the use of VRC significantly increased the probability of neurotoxicity, from $13.1 \%$ to $16.1 \%(\mathrm{OR}=1.99,95 \% \mathrm{CI}=1.05-3.75$, $P=0.03 ; I^{2}=55 \%$ ) (Fig. 4).

\section{Visual toxicity}

Visual toxicity could be analyzed for 13 RCTs involving 3940 patients [19-26, 28, 29, 31-33]. The pooled risk of an incidence of visual toxicity was $15.7 \%$ in the VRC group and $4.2 \%$ in the counterparts group (comprising combinations of various antifungals) $(\mathrm{OR}=6.50,95 \% \mathrm{CI}$ $=2.93-14.41, P<0.00001 ; I^{2}=77 \%$ ) (Fig. 5).

\section{Hepatotoxicity}

Hepatotoxicity could be analyzed for 14 RCTs involving 3529 patients [18-24, 26, 28-33]. The pooled risk of an elevation in liver enzyme levels was $13.6 \%$ in the VRC group and $17.7 \%$ in the counterparts group (comprising combinations of various antifungals) $(\mathrm{OR}=1.60,95 \% \mathrm{CI}$ $=1.17-2.19, P=0.003 ; I^{2}=39 \%$ ) (Fig. 6).

\section{Nephrotoxicity}

Nephrotoxicity could be analyzed for 9 RCTs involving 2530 patients [20-22, 28-32]. The rate of the abnormal renal function was significantly lower in the VRC group than in the counterparts group $(10.0 \%$ vs. $17.1 \%)(\mathrm{OR}=$ $0.46,95 \% \mathrm{CI}=0.26-0.84, P=0.02 ; I^{2}=67 \%$ ) (Fig. 7).

\section{Subgroup analysis}

In a further subgroup analysis by types of antifungal agents, therapeutic purpose, and duration, the risk of adverse events differed between treatment with VRC and other antifungals (Table 2).

The risk of discontinuation did not differ significantly between VRC and each single individual antifungal except for micafungin, which was associated with significantly reduced odds of discontinuation compared with VRC. According to the subgroup analysis of various treatment purposes, we found that VRC showed a significant poor tolerance in the definitive treatment compared with the empirical and prophylaxis treatment. Concerning the duration of treatment, VRC was more likely to be discontinued than other antifungal agents in patients treated for longer than 14 days. VRC was associated with significantly high risk of neurotoxicity compared with $\mathrm{AMB}$ and micafungin while other triazoles including fluconazole, itraconazole and isavuconazole failed to provide a significant reduction or increase in 


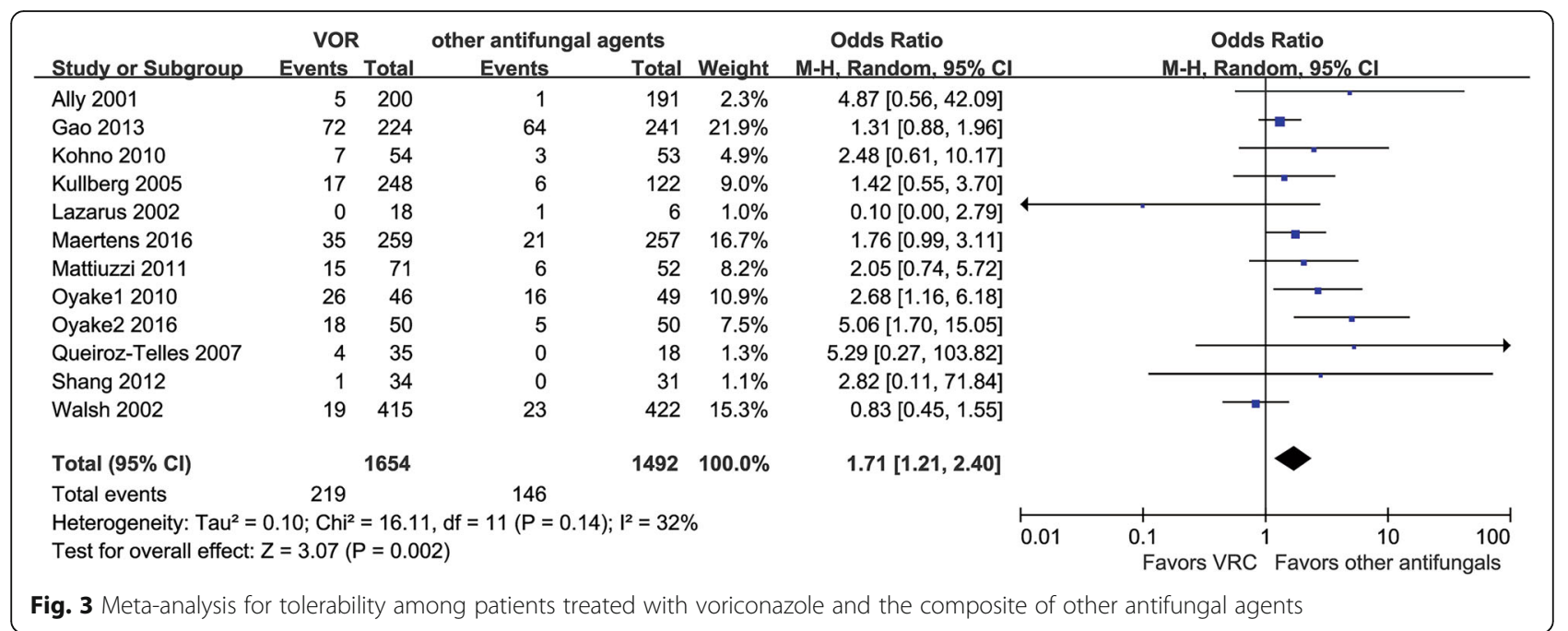

the incidence rate of neurotoxicity. Additionally, we also identified statistically significance in the odd of neurotoxicity in VRC versus other antifungal agents in the subgroup of empirical treatment and duration less than 14 days. Of notes, the studies involved in these two groups are the same, including the counterparts of AMB and micafungin, which may lead to this significant diffference owing to the antifungal type. However, there was no statistically significant difference in the group of definitive and prophylactic treatment as well as duration $\geq 14$ days. The high risk of visual toxicity during VRC treatment was consistent across all analyzed subgroups and the heterogeneity was also reduced attribute to the stratification of three subgroups analysis. For the outcome of hepatotoxicity, VRC showed a higher risk of abnormal liver enzyme levels compared with itraconazole, micafungin, and isavuconazole, but not for fluconazole or AMB. Patients who were diagnosed as definitive IFIs had a high risk of the elevation of liver enzyme levels in the VRC group. In addition, a duration of at least 2 weeks seemed to be a risk factor for liver injury when patients were treated with VRC rather than other antifungals. The heterogeneity of hepatotoxicity was also reduced by stratifying the data by all three subgroups. The occurrence of abnormal renal function did not differ significantly between VRC and the other antifungal agents except AMB, which was associated with a higher risk of nephrotoxicity. The probability of abnormal renal function in definitive and empirical fungal therapies was lower for VRC than for the composite of the other five antifungals. However, the risk of nephrotoxicity was significantly higher for patients treated with other antifungals than for VRC for treatment durations shorter than 14 days.

\section{Sensitivity analysis}

The sensitivity analysis verified the robustness of the findings for each outcome. A leave-one-out sensitivity analysis showed that no individual study excessively influenced the pooled effect in our meta-analysis except

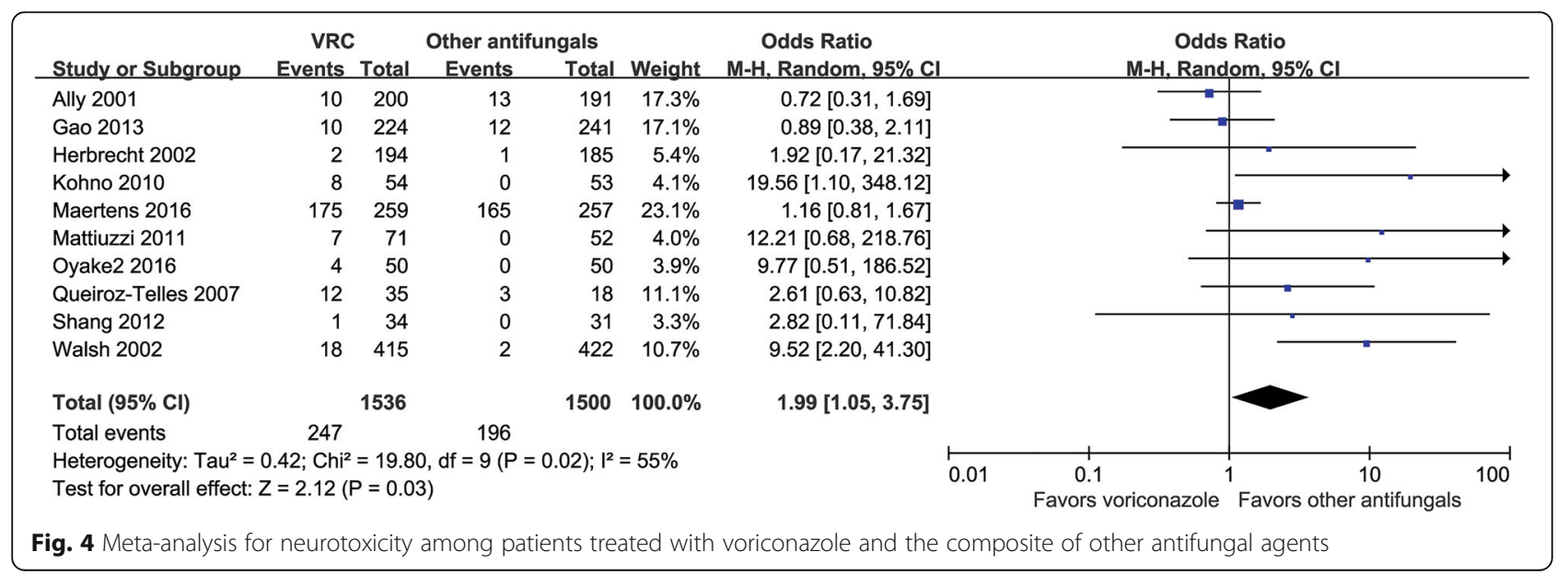




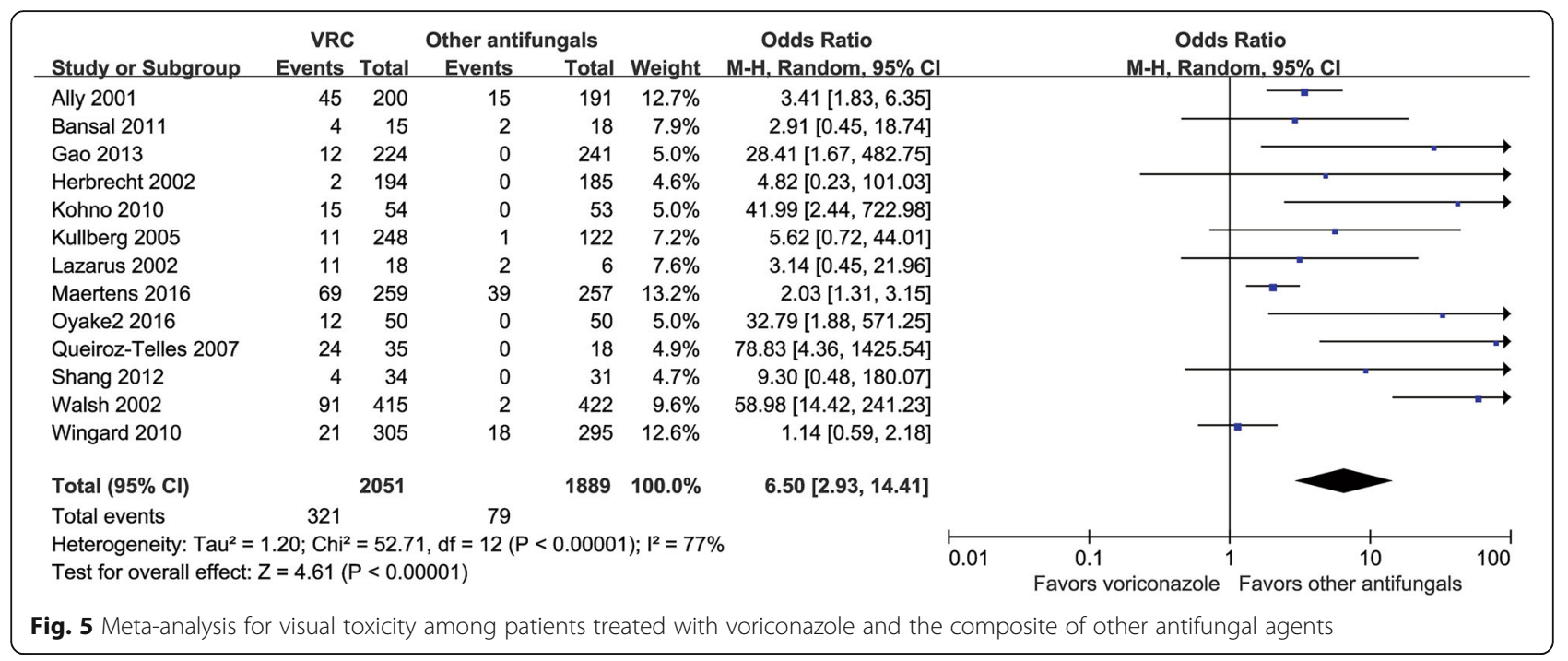

for the outcome of neurotoxicity (see Additional file 2: Figs. S1-S5), which was affected by removing 5 single study (including studies of Walsh, Queiroz-Telles, Kohno, Mattiuzzi and Oyake 2 [21, 26, 29, 30, 32]). In addition, the results for each outcome remained stable after excluding RCTs with samples smaller than 50, with a single-center design or with a high risk of bias (see in Additional file 3: Table S1).

\section{Discussion}

This meta-analysis found that the pooled risks of the primary and other four secondary safety outcomes differed significantly between VRC and the composite of other antifungal treatments. VRC was associated with higher risks of treatment discontinuation, neurotoxicity, visual toxicity, and hepatotoxicity but a lower risk of nephrotoxicity compared with the other antifungals.

The combined discontinuation rate of VRC was $13.2 \%$ in our meta-analysis. Wang found a discontinuation rate of $9.5 \%$, but this slight discrepancy could have been due to that study involving only three RCTs [4]. According to the results of the present meta-analysis of the primary outcome of tolerability, patients treated with VRC were more likely to discontinue therapy compared with the composite of the other five antifungals. However, the significant difference between these two groups could disappear when they were grouped according to specific drugs. The heterogeneity associated with multiple drugs could explain this change, while the therapeutic purpose and duration of therapy might also have influenced the final results. Patients with definitive IFIs and longer

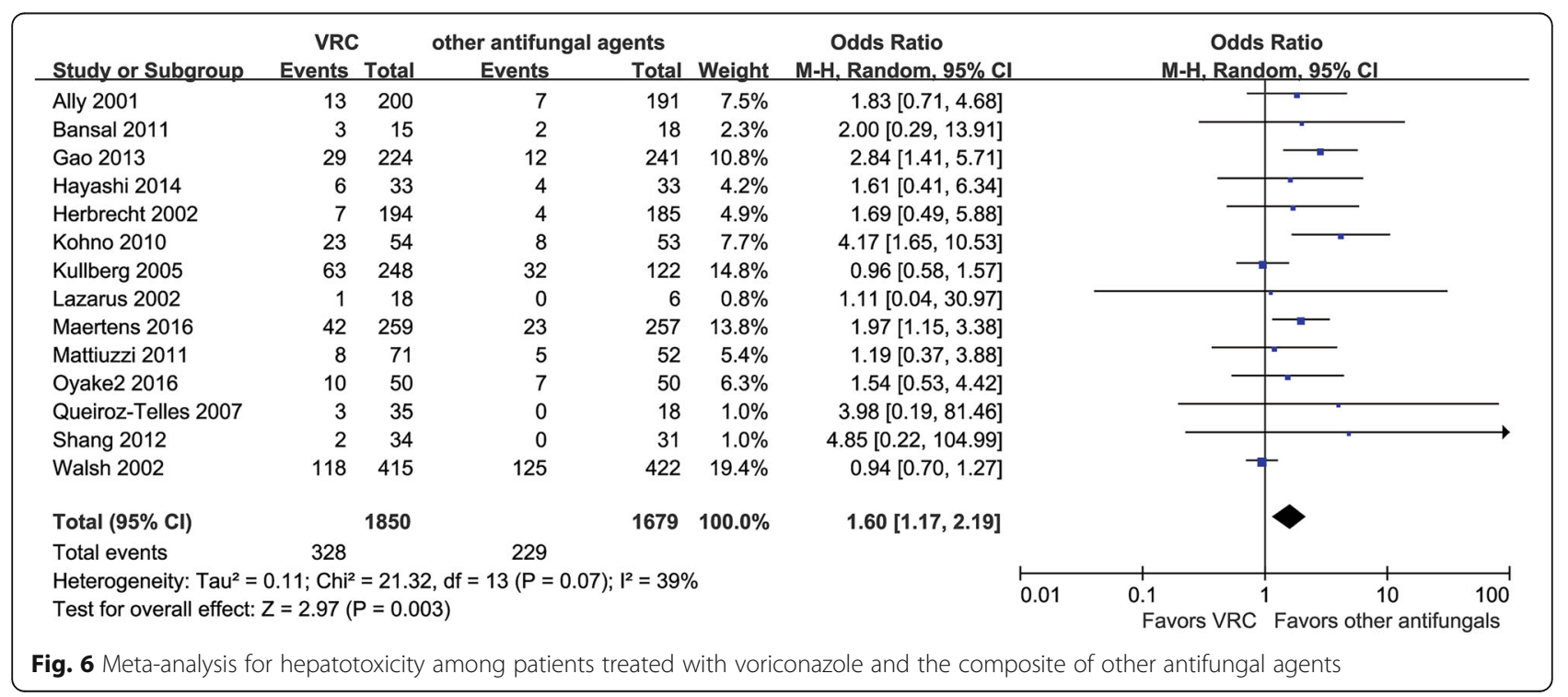




\begin{tabular}{|c|c|c|c|c|c|c|c|c|c|}
\hline \multirow[b]{2}{*}{ tudy or Subgroup } & \multicolumn{2}{|l|}{ VRC } & \multicolumn{3}{|c|}{ other antifungal agents } & \multirow{2}{*}{$\begin{array}{l}\text { Odds Ratio } \\
\text { M-H, Random, } 95 \% \mathrm{Cl}\end{array}$} & \multirow{2}{*}{\multicolumn{3}{|c|}{$\begin{array}{c}\text { Odds Ratio } \\
\mathrm{M}-\mathrm{H}, \text { Random, } 95 \% \mathrm{Cl}\end{array}$}} \\
\hline & Events & Total & Events & Total & Weight & & & & \\
\hline ansal 2011 & 0 & 15 & 11 & 18 & $3.4 \%$ & $0.02[0.00,0.41]$ & & & \\
\hline erbrecht 2002 & 2 & 194 & 19 & 185 & $9.8 \%$ & $0.09[0.02,0.40]$ & & & \\
\hline ohno 2010 & 1 & 54 & 1 & 53 & $3.8 \%$ & $0.98[0.06,16.10]$ & & & \\
\hline ullberg 2005 & 22 & 248 & 28 & 122 & $19.6 \%$ & $0.33[0.18,0.60]$ & & & \\
\hline laertens 2016 & 58 & 259 & 55 & 257 & $22.0 \%$ & $1.06[0.70,1.61]$ & & & 一 \\
\hline lattiuzzi 2011 & 1 & 71 & 0 & 52 & $3.0 \%$ & $2.23[0.09,55.94]$ & & & \\
\hline 'yake2 2016 & 1 & 50 & 1 & 50 & $3.8 \%$ & $1.00[0.06,16.44]$ & & & \\
\hline hang 2012 & 6 & 34 & 8 & 31 & $12.3 \%$ & $0.62[0.19,2.03]$ & & & - \\
\hline lalsh 2002 & 43 & 415 & 80 & 422 & $22.2 \%$ & $0.49[0.33,0.74]$ & & r & \\
\hline otal $(95 \% \mathrm{Cl})$ & & 1340 & & 1190 & $100.0 \%$ & $0.46[0.26,0.84]$ & & & \\
\hline otal events & 134 & & 203 & & & & & & \\
\hline $\begin{array}{l}\text { eterogeneity: } \mathrm{Tau}^{2}= \\
\text { est for overall effect }\end{array}$ & $\begin{array}{l}0.37 ; \mathrm{Chi}^{2} \\
\mathrm{Z}=2.54(\end{array}$ & $\begin{array}{l}=24.2 \\
P=0.0\end{array}$ & $\begin{array}{l}\text { 1, } d f=8(P=0 \\
\text { 1) }\end{array}$ & $1^{2}=67^{\circ}$ & & & 0.01 & $\begin{array}{l}0.1 \\
\text { Favors VRC }\end{array}$ & $\begin{array}{lcc}1 & 10 & 100 \\
\text { Favors antifungal agents }\end{array}$ \\
\hline
\end{tabular}

treatment durations were more vulnerable to discontinuation of VRC than the counterparts, which could be due to the severe underlying condition and long-term drug accumulation. Sensitivity analysis based on the small sample size $(n<50)$, single center and high risk of bias did not significantly change the results. However, it should be noted that all of the outcomes in our results need to be interpreted with caution since the counterpart of the VRC group was defined as a composite of antifungal agents rather than a single antifungal.

VRC-associated neurotoxicity, especially hallucination, is a common type of toxicity that is considered to significantly limit its application in the clinic [5, $11,34]$. Our findings indicated that the pooled risk of neurotoxicity for patients treated with VRC was almost twice higher than for those treated with other antifungals. Subgroup analysis indicated that VRC had similar incidence of neurotoxicity with trizoles (excluded of posaconazole) while a higher risk of neurotoxicity compared with $\mathrm{AMB}$ and micafungin. Zonios [34] exclusively investigated the incidence of hallucinations associated with VRC therapy, and found a rate of $16.6 \%$, which is similar as our result $(16.1 \%$ for the pooled incidence of neurotoxicity).

VRC-associated visual disturbance is also a common type of toxicity according to clinical observation [21, 24, $28,35,36]$. Our main findings indicated that the pooled risk of visual events for patients treated with VRC was 6.5 fold higher than for those treated with other antifungals. Subgroup analysis demonstrated that the incidence of visual disturbance still differed significantly between VRC and other antifungals in each single subgroup even though there were some variations in ORs. The pooled risk of visual toxicity showed the highest gap (15.7\% in VRC vs. $4.2 \%$ in the counterpart) among all of the observed toxicity outcomes. These two adverse events, neurotoxic and visual adverse events, although usually reversible, often lead to premature discontinuation of VRC [28].

The pooled risk of VRC-associated hepatotoxicity in our analysis (17.7\%) was similar to that found by Wang (19.7\%) [4]. We found that the risk of hepatotoxicity was higher for VRC than for any combination of the other five antifungals. VRC was involved in occurrence of hepatotoxicity in the definitive treatment group but not in the empirical and prophylactic treatment groups; the severe underlying condition and infectious situation may have contributed to this difference. A longer treatment duration also influenced the risk of hepatotoxicity.

The risk of nephrotoxicity was lower in the VRC group, but only AMB showed a significant higher risk of nephrotoxicity in the subgroup analysis, which was consistent with other studies [6, 37]. Unexpectedly, the nephrotoxicity risk was found to differ significantly between these two groups when the treatment duration was shorter than 14 days [21, 32]. These two studies compared VRC with liposomal AMB and micafungin, respectively. The probability of nephrotoxicity was the same in the RCT comparing VRC and micafungin, meaning that the result was due to the RCT comparing VRC with AMB [21]. A high AMB-induced nephrotoxicity could explain this result. The small number of studies and the combination of heterogeneous antifungals in the counterparts group could be the root cause of the unexpected results and the significant heterogeneity in nephrotoxicity outcomes.

Another newly released triazole antifungal agent, posaconazole, showed similar treatment-related adverse events with fluconazole for prophylaxis in severe Graftversus-Host Disease [38]. Additionally, patient receiving voriconazole was proved to have more treatment-related adverse events than those receiving fluconazole [39]. Thus posaconazole seems to cause less adverse events than voriconazole according to this indirect evidence. 
Table 2 Summary of subgroup analysis for the safety of voriconazole and other antifungals

\begin{tabular}{|c|c|c|c|c|c|c|c|c|}
\hline \multirow[t]{2}{*}{ Outcome } & \multirow[t]{2}{*}{ Subgroup } & \multirow[t]{2}{*}{ Variables } & \multirow[t]{2}{*}{ No. of studies } & \multicolumn{2}{|c|}{ No. of patients } & \multirow[t]{2}{*}{ OR $(95 \%$ Cl) } & \multirow[t]{2}{*}{$R^{2} \%$} & \multirow[t]{2}{*}{$P$} \\
\hline & & & & VRC & counterpart & & & \\
\hline \multirow[t]{10}{*}{ Tolerability } & \multirow[t]{5}{*}{ Antifungals } & FLU & 2 & $5 / 218$ & 2/197 & $0.86(0.02,38.38)$ & 73 & 0.94 \\
\hline & & AMB & 1 & $19 / 415$ & $23 / 422$ & $0.83(0.45,1.55)$ & NA & 0.56 \\
\hline & & ITRA & 3 & $91 / 330$ & $70 / 311$ & $1.42(0.98,2.06)$ & 0 & 0.06 \\
\hline & & MCF & 4 & $52 / 184$ & $24 / 183$ & $3.19[1.77,5.76]$ & 0 & 0.0001 \\
\hline & & ISA & 1 & $35 / 259$ & $21 / 257$ & $1.76(0.99,3.11)$ & NA & 0.05 \\
\hline & \multirow[t]{3}{*}{ Therapeutic purpose } & definitive & 6 & $69 / 830$ & $31 / 672$ & $1.87[1.20,2.92]$ & 0 & 0.005 \\
\hline & & empirical & 3 & $63 / 511$ & $44 / 521$ & $2.10(0.72,6.15)$ & 80 & 0.18 \\
\hline & & prophylaxis & 3 & $87 / 313$ & $71 / 299$ & $1.35(0.67,2.69)$ & 34 & 0.40 \\
\hline & \multirow[t]{2}{*}{ Duration } & $<14 d$ & 3 & $63 / 511$ & $44 / 521$ & $2.10(0.72,6.15)$ & 80 & 0.18 \\
\hline & & $\geq 14 d$ & 9 & $156 / 1143$ & 102/971 & $1.54[1.16,2.05]$ & 0 & 0.003 \\
\hline \multirow[t]{10}{*}{ Neurotoxicity } & \multirow[t]{5}{*}{ Antifungals } & FLU & 1 & $10 / 200$ & $13 / 191$ & $0.72[0.31,1.69]$ & NA & 0.45 \\
\hline & & AMB & 2 & $20 / 609$ & $3 / 607$ & $6.87[2.04,23.16]$ & 21 & 0.002 \\
\hline & & ITRA & 3 & $29 / 330$ & $15 / 311$ & $1.62[0.84,3.14]$ & 52 & 0.15 \\
\hline & & MCF & 3 & $13 / 138$ & $0 / 134$ & $10.28[1.91,55.44]$ & 0 & 0.007 \\
\hline & & ISA & 1 & $175 / 259$ & $165 / 257$ & $1.16[0.81,1.67]$ & NA & 0.42 \\
\hline & \multirow[t]{3}{*}{ Therapeutic purpose } & definitive & 6 & 208/776 & 182/735 & $1.27[0.93,1.73]$ & 26 & 0.13 \\
\hline & & empirical & 2 & $22 / 465$ & $2 / 472$ & $9.57[2.57,35.60]$ & 0 & 0.0008 \\
\hline & & prophylaxis & 2 & $17 / 295$ & $12 / 293$ & $1.40[0.66,2.97]$ & 69 & 0.39 \\
\hline & \multirow[t]{2}{*}{ Duration } & $\geq 14 d$ & 8 & 225/1071 & 194/1028 & $1.29[0.97,1.72]$ & 29 & 0.08 \\
\hline & & $<14 d$ & 2 & $22 / 465$ & $2 / 472$ & $9.57[2.57,35.60]$ & 0 & 0.0008 \\
\hline \multirow[t]{10}{*}{ Visual toxicity } & \multirow[t]{5}{*}{ Antifungals } & FLU & 3 & $77 / 523$ & $35 / 492$ & $2.11[1.38,3.24]$ & 66 & 0.0006 \\
\hline & & $\mathrm{AMB}$ & 3 & $97 / 624$ & $4 / 625$ & $28.83[10.84,76.64]$ & 75 & $<0.00001$ \\
\hline & & ITRA & 2 & $37 / 259$ & $0 / 259$ & $46.57[5.89,368.06]$ & 0 & 0.0003 \\
\hline & & MCF & 3 & $31 / 138$ & $0 / 134$ & $26.63[5.15,137.62]$ & 0 & $<0.0001$ \\
\hline & & ISA & 1 & $69 / 259$ & $39 / 257$ & $2.03[1.31,3.15]$ & NA & 0.002 \\
\hline & \multirow[t]{3}{*}{ Therapeutic purpose } & definitive & 8 & 175/1039 & $57 / 875$ & $3.33[2.41,4.59]$ & 49 & $<0.00001$ \\
\hline & & empirical & 2 & $103 / 465$ & $2 / 472$ & $53.85[15.23,190.37]$ & 0 & $<0.00001$ \\
\hline & & prophylaxis & 3 & $44 / 547$ & $20 / 542$ & $1.93[1.11,3.36]$ & 68 & 0.02 \\
\hline & \multirow[t]{2}{*}{ Duration } & $<14 d$ & 11 & 219/1586 & $77 / 1417$ & $2.92[2.21,3.85]$ & 57 & $<0.00001$ \\
\hline & & $\geq 14 d$ & 2 & $103 / 465$ & $2 / 472$ & $53.85[15.23,190.37]$ & 0 & $<0.00001$ \\
\hline \multirow[t]{10}{*}{ Hepatotoxicity } & \multirow[t]{5}{*}{ Antifungals } & FLU & 2 & $14 / 218$ & $7 / 197$ & $1.76(0.71,4.36)$ & 0 & 0.22 \\
\hline & & $\mathrm{AMB}$ & 3 & $128 / 624$ & $131 / 625$ & $0.99(0.74,1.32)$ & 0 & 0.95 \\
\hline & & ITRA & 4 & $46 / 363$ & $21 / 344$ & $2.19(1.27,3.76)$ & 0 & 0.005 \\
\hline & & MCF & 3 & $35 / 138$ & $15 / 134$ & $2.78(1.38,5.60)$ & 4 & 0.004 \\
\hline & & ISA & 1 & $42 / 259$ & $23 / 257$ & $1.97(1.15,3.38)$ & NA & 0.01 \\
\hline & Therapeutic purpose & definitive & 8 & 156/1039 & $76 / 875$ & $1.79(1.18,2.71)$ & 29 & 0.006 \\
\hline & & empirical & 2 & $128 / 465$ & $132 / 472$ & $0.98(0.73,1.30)$ & 0 & 0.88 \\
\hline & & prophylaxis & 4 & $44 / 346$ & $21 / 332$ & $2.11(1.22,3.63) 0$ & 0 & 0.07 \\
\hline & Duration & $<14 d$ & 2 & $128 / 465$ & $132 / 472$ & $0.98(0.73,1.30)$ & 0 & 0.88 \\
\hline & & $\geq 14 d$ & 11 & 194/1352 & $93 / 1174$ & $1.82(1.31,2.54)$ & 19 & 0.0003 \\
\hline Nephrotoxicity & Antifungals & FLU & 0 & NA & NA & NA & NA & NA \\
\hline & & AMB & 3 & $45 / 624$ & $110 / 625$ & $0.15(0.03,0.84)$ & 78 & 0.03 \\
\hline & & ITRA & 1 & $1 / 71$ & $0 / 52$ & $2.23(0.09,55.94)$ & NA & 0.62 \\
\hline
\end{tabular}


Table 2 Summary of subgroup analysis for the safety of voriconazole and other antifungals (Continued)

\begin{tabular}{|c|c|c|c|c|c|c|c|c|}
\hline \multirow[t]{2}{*}{ Outcome } & \multirow[t]{2}{*}{ Subgroup } & \multirow[t]{2}{*}{ Variables } & \multirow[t]{2}{*}{ No. of studies } & \multicolumn{2}{|c|}{ No. of patients } & \multirow[t]{2}{*}{ OR $(95 \% \mathrm{Cl})$} & \multirow[t]{2}{*}{$P^{2} \%$} & \multirow[t]{2}{*}{$P$} \\
\hline & & & & VRC & counterpart & & & \\
\hline & & MCF & 3 & 8/138 & $10 / 134$ & $0.70(0.25,1.94)$ & 0 & 0.49 \\
\hline & \multirow{4}{*}{ Therapeutic purpose } & ISA & 1 & $58 / 259$ & $55 / 257$ & $1.06(0.70,1.61)$ & NA & 0.79 \\
\hline & & definitive & 6 & $89 / 804$ & $122 / 666$ & $0.36(0.14,0.91)$ & 78 & 0.03 \\
\hline & & empirical & 2 & $44 / 465$ & $81 / 472$ & $0.50(0.34,0.74)$ & 0 & 0.0006 \\
\hline & & prophylaxis & 1 & $1 / 71$ & $0 / 52$ & $2.23(0.09,55.94)$ & NA & 0.62 \\
\hline & \multirow[t]{2}{*}{ Duration } & $<14 d$ & 2 & $44 / 465$ & $81 / 472$ & $0.50(0.34,0.74)$ & 0 & 0.0006 \\
\hline & & $\geq 14 d$ & 7 & $90 / 875$ & $122 / 718$ & $0.41(0.17,0.98)$ & 74 & 0.05 \\
\hline
\end{tabular}

NA not applicable

There were also some studies which use posaconazole as a substitution of voriconazole due to its intolerance [40, 41]. However, there is no RCT comparing voriconazole and posaconazole in safety area. Further studies are needed in this respect.

\section{Strengths and weaknesses}

The previous meta-analysis regarding the status of voriconazole among all antifungal agents mostly focused on the efficacy and pharmacoeconomics [42-44]. To our knowledge, this is the first study to have comprehensively compared five common adverse events induced by VRC and other antifungals by systematically reviewing RCTs. The results can be used by clinicians to avoid unnecessary adverse effects and select a better antifungal therapeutic scheme for patients. Furthermore, we also quantified the specific outcomes concerning different antifungals, treatment purposes, and durations by subgroup analysis for four safety outcomes.

Several limitations of our study should be considered. First, as is inevitable for any meta-analysis, our study shares the limitations of the original studies. However, we performed the largest pooled comparison of the toxicity profiles of VRC and a composite of other common antifungal agents based on RCTs. Second, we directly used the criteria applied in each study because the thresholds for abnormal liver and renal enzyme levels varied between them. Finally, the combination of various antifungals in the counterparts group may have been responsible for the moderate heterogeneity and a certain degree of publication bias among the studies (see in Additional file 4: Figure S6). The present findings therefore need to be confirmed in future high-quality studies.

\section{Conclusion}

This meta-analysis provides a comprehensive synthesis of the evidence of harm that voriconazole is associated with higher pooled risk of treatment discontinuation, neurotoxicity, visual toxicity, hepatotoxicity but a lower risk of nephrotoxicity compared with other antifungal agents based on the evidence of current RCTs. The results could point to alternative treatments for a patient with a certain antifungal intolerance, thereby helping the clinician select the optimal intervention.

\section{Additional files}

Additional file 1: Detailed searching strategy. It provided more detail about the searching strategy we used in the present study. (PDF $105 \mathrm{~kb}$ )

Additional file 2: Sensitive analysis and the funnel plots under the five outcomes. The sensitive analysis part included the influence of individual study involved in the evaluation of tolerability, neurotoxicity, visual toxicity, hepatotoxicity and nephrotoxicity (see in Figure S1-S5). (PDF $433 \mathrm{~kb}$ )

Additional file 3: A summary of sensitive analysis for voriconazole safety after excluding a group of studies which was considered as the potential impact factors to the final results was shown in Table S1. (PDF $33 \mathrm{~kb}$ )

Additional file 4: The funnel plots for the tolerability, neurotoxicity, visual toxicity, hepatotoxicity, and nephrotoxicity were presented in Figure S6. (PDF 238 kb)

\section{Abbreviations}

AHSCT: allogeneic hematopoietic stem cell transplantation; AMB: amphotericin B; AMB: amphotericin B; AMBD: amphotericin B deoxycholate; AML: acute myeloid leukemia; Cis: confidence intervals; CISA: chronic invasive sinus aspergillosis; CTCAE: Common Terminology Criteria for Adverse Events; D: definitive treatment; E: empirical treatment; EORTC/MSG: European Organization for Research and Treatment of Cancer/ Invasive Fungal Infections Cooperative Group and the National Institute of Allergy and Infectious Diseases Mycoses Study Group; FLU: fluconazole; FN: febrile neutropenia; HM: hematological malignancy; IFIs: invasive fungal infections; ISA: isavuconazole; ITRA: itraconazole; LAMB: liposome amphotericin B; MCF: micafungin; MDS: myelodysplastic syndrome; N: No; NA: not available; OR: Odds ratios; P: prophylaxis; RCTs: randomized controlled trials; SOT: solid organ transplantation; VRC: voriconazole; VRC: voriconazole; Y: Yes

\section{Acknowledgements}

Not applicable.

Funding

This work was supported by the Chinese Medical Association (No. 16010120628) and the 17th "Tengfei Cup" extracurricular academic science and technology works competition of Xi 'an Jiaotong University.

\section{Availability of data and materials}

All data generated or analyzed during this study are included in this published article [and its additional files]. 


\section{Authors' contributions}

Conceived and designed the protocol: LJ. Execution of search strategy and data extraction: $X Y M, C L, F Y, Z Y$. Data analysis and interpretation: $X Y M, C L$, FY, ZY, ZYJ. Drafting manuscript: XYM, CL, ZYJ. All authors have read and approved the final manuscript.

\section{Ethics approval and consent to participate}

No ethical approval was sought, because approval was deemed unnecessary for this meta-analysis.

\section{Consent for publication}

Not applicable.

\section{Competing interests}

The authors declare that they have no competing interests.

\section{Publisher's Note}

Springer Nature remains neutral with regard to jurisdictional claims in published maps and institutional affiliations.

\section{Author details}

'Clinical Research Center, The First Affiliated Hospital of Xi'an Jiaotong University, Xi'an 710061, China. ${ }^{2}$ Hou Zonglian medical experimental class of 2014, Xi'an Jiaotong University, Xi'an 710061, China. ${ }^{3}$ Department of Pharmacy, The First Affiliated Hospital of Xi'an Jiaotong University, Xi'an 710061, China. ${ }^{4}$ Hou Zonglian medical experimental class of 2015, Xi'an Jiaotong University, Xi'an 710061, China.

\section{Received: 2 July 2017 Accepted: 13 December 2017}

\section{Published online: 28 December 2017}

\section{References}

1. Ascioglu S, Rex JH, de Pauw B, Bennett JE, Bille J, Crokaert F, et al. Defining opportunistic invasive fungal infections in immunocompromised patients with cancer and hematopoietic stem cell transplants: an international consensus. Clin Infect Dis. 2002;34:7-14.

2. Patterson TF, Thompson GR, 3rd, Denning DW, Fishman JA, Hadley S, Herbrecht $R$ et al: Practice guidelines for the diagnosis and Management of Aspergillosis: 2016 update by the Infectious Diseases Society of America. Clin Infect Dis 2016; 63:e1-e60.

3. Pappas PG, Kauffman CA, Andes DR, Clancy CJ, Marr KA, Ostrosky-Zeichner $L$, et al. Clinical practice guideline for the Management of Candidiasis: 2016 update by the Infectious Diseases Society of America. Clin Infect Dis. 2016;62:e1-50

4. Wang $\mathrm{J}$, Chang $\mathrm{CH}$, Young-Xu Y, Chan KA. Systematic review and metaanalysis of the tolerability and hepatotoxicity of antifungals in empirical and definitive therapy for invasive fungal infection. Antimicrob Agents Chemother. 2010;54:2409-19.

5. Halpern AB, Lyman GH, Walsh TJ, Kontoyiannis DP, Walter RB. Primary antifungal prophylaxis during curative-intent therapy for acute myeloid leukemia. Blood. 2016;126:2790-7.

6. Kontoyiannis DP. Invasive mycoses: strategies for effective management. Am Med. 2012;125:S25-38

7. Horn D, Goff D, Khandelwal N, Spalding J, Azie N, Shi F, et al. Hospital resource use of patients receiving isavuconazole vs voriconazole for invasive mold infections in the phase III SECURE trial. J Med Econ. 2016;19:728-34.

8. Robenshtok E, Gafter-Gvili A, Goldberg E, Weinberger M, Yeshurun M, Leibovici $L$, et al. Antifungal prophylaxis in cancer patients after chemotherapy or hematopoietic stem-cell transplantation: systematic review and meta-analysis. J Clin Oncol. 2007;25:5471-89.

9. Nagappan $\vee$, Deresinski S. Reviews of anti-infective agents: posaconazole: a broad-spectrum triazole antifungal agent. Clin Infect Dis. 2007;45:1610-7.

10. Guarascio AJ, Slain D. Review of the new delayed-release oral tablet and intravenous dosage forms of posaconazole. Pharmacotherapy. 2015;35:208-19.

11. Thompson GR, Lewis JS. Pharmacology and clinical use of voriconazole. Expert opinion on drug metabolism and. Toxicology. 2010;6:83-94.

12. Scott LJ. Micafungin: a review of its use in the prophylaxis and treatment of invasive Candida infections. Drugs. 2012;72:2141-65.

13. Shirley $M$, Scott LJ. Isavuconazole: a review in invasive aspergillosis and Mucormycosis. Drugs. 2016;76:1647-57.
14. Imhof A, Walter RB, Schaffner A. Continuous infusion of escalated doses of amphotericin B deoxycholate: an open-label observational study. Clin Infect Dis. 2003;36:943-51.

15. Falagas ME, Ntziora F, Betsi Gl, Samonis G. Caspofungin for the treatment of fungal infections: a systematic review of randomized controlled trials. Int J Antimicrob Agents. 2007:29:136-43.

16. CTCAE (Common Terminology Criteria for Adverse Events);Common Terminology Criteria for Adverse Events (CTCAE) Version 4.0 Published: May 28 vJ, 2010): Common Terminology Criteria for Adverse Events (CTCAE) Version 4.0 Published: May 28, 2009 (v4.03: Ju. 2009.

17. Higgins JPT, Green D. Cochrane handbook for systematic reviews of interventions. Version 5.1.0. Cochrane Collaboration, 2011. http://www. cochrane-handbook.org.

18. Hayashi Y, Kanda Y, Nakamae H, Kanamori H, Ohashi K, Hidaka M, et al. Voriconazole Vs. Itraconazole for antifungal prophylaxis in patients with GVHD: A randomized trial Biology of Blood and Marrow Transplantation. 2014:20:S91.

19. Herbrecht R, Denning DW, Patterson TF, Bennett JE, Greene RE, Oestmann JW, et al. Voriconazole versus amphotericin B for primary therapy of invasive aspergillosis. N Engl J Med. 2002;347:408-15.

20. Kullberg BJ, Sobel JD, Ruhnke M, Pappas PG, Viscoli C, Rex JH, et al. Voriconazole versus a regimen of amphotericin $B$ followed by fluconazole for candidaemia in non-neutropenic patients: a randomised non-inferiority trial. Lancet. 2005;366:1435-42.

21. Walsh TJ, Pappas P, Winston DJ, Lazarus HM, Petersen F, Raffalli J, et al. Voriconazole compared with liposomal amphotericin B for empirical antifungal therapy in patients with neutropenia and persistent fever. N Engl J Med. 2002:346:225-34

22. Bansal S, Gupta AK. Should voriconazole be the primary therapy for chronic invasive sinus aspergillosis (CISA)? Clinical. Rhinology. 2011;4:21-6.

23. Lazarus HM, Blumer JL, Yanovich S, Schlamm H, Romero A. Safety and pharmacokinetics of oral voriconazole in patients at risk of fungal infection: a dose escalation study. J Clin pharmacol. 2002;42:395-402.

24. Ally R, Schürmann D, Kreisel W, Carosi G, Aguirrebengoa K, Dupont B, et al. A randomized, double-blind, double-dummy, multicenter trial of voriconazole and fluconazole in the treatment of esophageal candidiasis in immunocompromised patients. Clin Infect Dis. 2001;33:1447-54.

25. Wingard JR, Carter SL, Walsh TJ, Kurtzberg J, Small TN, Baden LR, et al. Randomized, double-blind trial of fluconazole versus voriconazole for prevention of invasive fungal infection after allogeneic hematopoietic cell transplantation. Blood. 2010;116:5111-8.

26. Queiroz-Telles F, Goldani LZ, Schlamm HT, Goodrich JM, Espinel-Ingroff A, Shikanai-Yasuda MA. An open-label comparative pilot study of oral voriconazole and itraconazole for long-term treatment of paracoccidioidomycosis. Clin Infect Dis. 2007;45:1462-9.

27. Oyake T, Kowata S, Murai K, Ito S, Akagi T, Kubo K, et al. Micafungin versus voriconazole for empirical antifungal therapy in febrile neutropenic patients with acute myeloid leukemia: a randomized, controlled trial. Blood. 2010;116

28. Maertens JA, Raad, II, Marr KA, Patterson TF, Kontoyiannis DP, Cornely OA et al: Isavuconazole versus voriconazole for primary treatment of invasive mould disease caused by aspergillus and other filamentous fungi (SECURE): a phase 3, randomised-controlled, non-inferiority trial. In: Lancet (London, England) vol 387; 2016: 760-769.

29. Kohno S, Izumikawa K, Ogawa K, Kurashima A, Okimoto N, Amitani R, et al. Intravenous micafungin versus voriconazole for chronic pulmonary aspergillosis: a multicenter trial in Japan. J Inf Secur. 2010;61:410-8.

30. Mattiuzzi GN, Cortes J, Alvarado G, Verstovsek S, Koller C, Pierce S, et al. Efficacy and safety of intravenous voriconazole and intravenous itraconazole for antifungal prophylaxis in patients with acute myelogenous leukemia or high-risk myelodysplastic syndrome. Support Care Cancer. 2011;19:19-26.

31. Shang W, Feng G, Sun R, Wang X, Liu W, Zhang S, et al. Comparison of micafungin and voriconazole in the treatment of invasive fungal infections in kidney transplant recipients. J Clin Pharmacy Therapeutics. 2012;37:652-6.

32. Oyake T, Kowata S, Murai K, Ito S, Akagi T, Kubo K, et al. Comparison of micafungin and voriconazole as empirical antifungal therapies in febrile neutropenic patients with hematological disorders: a randomized controlled trial. Eur J Haematol. 2016;96:602-9.

33. Gao X, Marks DI, Schlamm HT, Ji X, Stephens JM, Tarallo M. Association between drug tolerability and medical resource use in prophylaxis of invasive fungal infections after allogeneic hematopoietic stem cell transplant. J Medical Economics. 2013;16:1061-70. 
34. Zonios DI, Gea-Banacloche J, Childs R, Bennett JE. Hallucinations during voriconazole therapy. Clin Infect Dis. 2008;47:e7-e10.

35. Kadikoy H, Barkmeier A, Peck B, Carvounis PE. Persistent photopsia following course of oral voriconazole. J Ocul Pharmacol Ther. 2010;26:387-8.

36. Eiden C, Peyriere H, Cociglio M, Djezzar S, Hansel S, Blayac JP, et al. Adverse effects of voriconazole: analysis of the French pharmacovigilance database. Ann Pharmacother. 2007;41:755-63.

37. Safdar A, Ma J, Saliba F, Dupont B, Wingard JR, Hachem RY, et al. Druginduced nephrotoxicity caused by amphotericin B lipid complex and liposomal amphotericin B: a review and meta-analysis. Medicine (Baltimore). 2010;89:236-44.

38. Ullmann AJ, Lipton JH, Vesole DH, Chandrasekar P, Langston A, Tarantolo $\mathrm{SR}$, et al. Posaconazole or fluconazole for prophylaxis in severe graft-versushost disease. N Engl J Med. 2007;356:335-47.

39. Ally R, Schurmann D, Kreisel W, Carosi G, Aguirrebengoa K, Dupont B, et al. A randomized, double-blind, double-dummy, multicenter trial of voriconazole and fluconazole in the treatment of esophageal candidiasis in immunocompromised patients. Clin Infect Dis. 2001;33:1447-54.

40. Heinz WJ, Egerer G, Lellek H, Boehme A, Greiner J. Posaconazole after previous antifungal therapy with voriconazole for therapy of invasive aspergillus disease, a retrospective analysis. Mycoses. 2013;56:304-10.

41. Jacobsen AA, Papo YB, Sarro R, Weisse K, Strasswimmer J. Posaconazole substitution for Voriconazole-associated phototoxic effects. JAMA Dermatol. 2016;

42. Bow EJ, Vanness DJ, Slavin M, Cordonnier C, Cornely OA, Marks DI, et al. Systematic review and mixed treatment comparison meta-analysis of randomized clinical trials of primary oral antifungal prophylaxis in allogeneic hematopoietic cell transplant recipients. BMC Infect Dis. 2015;15:128.

43. Chen K, Wang Q, Pleasants RA, Ge L, Liu W, Peng K, et al. Empiric treatment against invasive fungal diseases in febrile neutropenic patients: a systematic review and network meta-analysis. BMC Infect Dis. 2017;17:159.

44. Leonart LP, Tonin FS, Ferreira VL, Penteado STS, Wiens A, Motta FA et al: A network meta-analysis of primary prophylaxis for invasive fungal infection in haematological patients. 2017.

\section{Submit your next manuscript to BioMed Central and we will help you at every step:}

- We accept pre-submission inquiries

- Our selector tool helps you to find the most relevant journal

- We provide round the clock customer support

- Convenient online submission

- Thorough peer review

- Inclusion in PubMed and all major indexing services

- Maximum visibility for your research

Submit your manuscript at www.biomedcentral.com/submit

) Biomed Central 